\title{
Nanomedicine: Will it be able to Overcome Multidrug Resistance in Cancers?
}

\section{Sten Friberg*}

Department of Neuroscience, Swedish Medical Nanoscience Center, Karolinska Institutet, Retzius väg, Stockholm, Sweden

*Corresponding author: Sten Friberg, Department of Neuroscience, Swedish Medical Nanoscience Center, Karolinska Institutet, Retzius väg 8, 171 77, Stockholm, Sweden, Tel: +46 8524800 00; E-mail: proband@telia.com

Received date: Sep 09, 2016, Accepted date: Sep 15, 2016, Publication date: Sep 19, 2016

Copyright: (C) 2016 Friberg S. This is an open-access article distributed under the terms of the Creative Commons Attribution License, which permits unrestricted use, distribution, and reproduction in any medium, provided the original author and source are credited.

Citation: Friberg S (2016) Nanomedicine: Will it be able to Overcome Multidrug Resistance in Cancers? J Blood Disord Transfus 7: 368. doi: 10.4172/2155-9864.1000368

At present, every third individual in the Western world is diagnosed with a cancer at some point in their lives. In spite of great advances in oncology in recent decades, around $50 \%$ of these individuals will die from their diseases. The great majority of these deaths are caused by cancer cells endowed with multiple drug resistance (MDR). These cells are not eliminated by present-day therapies, and new strategies for general oncologic treatment are needed. The shape of such new treatments is emerging, and such treatments will likely be highly individualized, but at the same time highly complex and costly.

Multimodality is mandatory, and the treatment steps will be sequential.

The plausible major steps are likely to be:

1. Blocking of the genes responsible for MDR,

2. Killing of the adult cancer cells that are protecting the malignant stem cells. With the genes blocked in Step 1, the adult cancer cells will be more susceptible to toxic drugs. This will allow smaller amounts of therapeutic drugs to be used, leading to fewer toxic side effects,

3. The dead adult cancer cells must be removed to expose the dormant cancer stem cells. Dormant cancer cells are believed to be unaffected by present-day oncologic therapies,
4. Initiation of proliferation among the cancer stem cells which will make them susceptible to education or killing,

5. Killing of the malignant stem cells, or educating them to enter permanent dormancy and thus render them harmless.

For these five steps, the medical profession is already in possession of most of the needed therapeutic agents. However, some of these agents are toxic when given intravenously in humans, and some of them are inactivated during the transport in the blood. Nanoparticles might offer a dual benefit by protecting the patient from the agent, and simultaneously protecting the agent from the patient.

What is lacking is knowledge of the time needed for each step and of the potential side effects for each step.

Effective targeting methods currently exist for superficial tumors (both primary and secondary), but not for deep-seated cancers.

A more detailed version of this summary is found in:"Nanomedicine: will it offer possibilities to overcome multiple drug resistance in cancer?" J Nanobiotechnology. 